\title{
O papel do ambiente hospitalar na disseminação de bactérias resistentes
}

\author{
Adriana Cristina Oliveira' ${ }^{1}$, Quésia Souza Damasceno ${ }^{2}$ \\ ${ }^{1}$ Enfermeira. Pós-Doutora pela Universidade de Nova York. Professora Associada do Departamento \\ de Enfermagem Básica da Escola de Enfermagem (UFMG), Belo Horizonte - MG - Brasil. \\ adrianacoliveira@gmail.com \\ ${ }^{2}$ Enfermeira. Mestre em Enfermagem. Doutoranda em Enfermagem pelo Programa de \\ Pós-Graduação da Escola de Enfermagem (UFMG), Belo Horizonte - MG - Brasil. \\ qdamasceno@yahoo.com.br
}

As infecções relacionadas à assistência (IRAS) têm merecido destaque e atenção dos profissionais de saúde e pesquisadores desde os anos de 1950 quando estas começaram a se destacar como um importante evento adverso ocorrendo entre os pacientes internados nas instituições hospitalares.

E como evento adverso as possibilidades de transmissão, fatores causais e relação do cuidado prestado pelo profissional de saúde, ambiente, condições de esterilização do material usado e estado clínico do paciente se constituíram como foco dos primeiros estudos voltados para esta temática.

E neste contexto passou a merecer atenção o ambiente hospitalar como facilitador da transmissão das infecções pela possibilidade de atuar como provável reservatório para os microrganismos.

As práticas encontradas para esta época estavam relacionadas à "desinfecção do ambiente", com a utilização de diversos meios, sendo mais comum no Brasil o uso das pastilhas de formol em ambiente fechado. A recomendação para esta prática se estabelecia quase que de forma rotineira e empírica após o atendimento/internação de pacientes considerados infectados, seja pelo tipo de procedimento cirúrgico realizado ou até mesmo pela própria condição clínica do paciente. Todavia, o monitoramento ambiental como prática foi desaconselhado, devido à não associação das taxas de infecções com os níveis de contaminação do ar ou superfícies ambientais e, pela falta de padrões pré-estabelecidos de contaminação para essa avaliação ${ }^{1}$.

No Brasil são escassos estudos que descrevam estas práticas, até mesmo pela pouca produção científica referente ao tema ambiente e controle das infecções, adotada entre os anos de 1970-1990.

Entretanto, a relação cada vez mais estreita entre a infecção hospitalar até então denominada de forma restrita àquelas em decorrentes do cuidado nestes estabelecimentos e a emergência dos microrganismos multirresistentes traz novamente à tona discussões sobre o papel da contaminação de superfícies inanimadas ganhando destaque a partir dos anos de 2000.

Neste aspecto, os avanços relacionados à epidemiologia da resistência bacteriana como a descrição do seu mecanismo, caracterização genotípica e fenotípica, formas de transmissão dos microrganismos e impacto no cuidado de saúde como prolongamento das internações, custos com antimicrobianos e o aumento de óbitos entre os pacientes colonizados ou infectados por estes agentes, contribuíram fortemente para o retorno do tema em pauta para a prática assistencial e também para a academia.

Em relação à contaminação de superfícies inanimadas nos estabelecimentos de saúde, a Unidade de Terapia Intensiva (UTI) tem sido apontada 
como a de maior atenção devido à alta prevalência de microrganismos resistentes favorecida pela gravidade do paciente, instabilidade do seu quadro clínico e necessidade de cuidados intensivos, somados aos fatores como recursos humanos, limpeza da unidade, desinfecção e estrutura física ${ }^{3-5}$.

Diversos estudos em todo mundo ratificam a relevância do tema em questão, a exemplo, pode-se citar a verificação da permanência de Enterococcus spp. resistente à Vancomicina (VRE) em superfícies do ambiente hospitalar por até quatro meses. Neste caso, a contaminação ambiental por VRE tem sido conferida em ambiente ocupado por pacientes colonizados e/ou infectados por este microrganismo. Outro microrganismo frequentemente isolado e associado ao ambiente se refere ao Staphylococcus aureus resistente à meticilina (MRSA), presente na microbiota transitória das mãos dos profissionais de saúde e em superfícies do ambiente hospitalar sugerindo a contaminação cruzada ${ }^{1,6-9}$.

Nas superfícies próximas ao paciente, especialmente o leito, verificase a possibilidade de contaminação por Pseudomonas aeruginosa, Clostridium difficile, Acinetobacter baumannii, VRE e MRSA, sendo o último mais frequente, além de serem isolados em maçanetas, cadeiras, assentos sanitários, mesa, teclados de computador e diafragma do estetoscópio. Nas torneiras, destaca-se Pseudomonas aeruginosa, pelo tropismo positivo para locais úmidos ${ }^{1,10-13}$.

No Brasil, os primeiros estudos publicados voltados para a qualidade da limpeza hospitalar e seu possível impacto na qualidade assistencial podem ser encontrados a partir de 2000. Na avaliação da limpeza destaca-se a comparação da eficácia entre os métodos unidirecional e de movimentos circulares na desinfecção de colchões e, a variação da carga microbiana antes e depois da limpeza terminal. Quanto aos resultados preocupa a questão da permanência da carga microbiana após a limpeza comprovando a necessidade de avaliação periódica do processo de limpeza/desinfecção utilizado visando uma maior segurança no ambiente hospitalar ${ }^{14}$.

Os primeiros estudos sobre o ambiente estiveram voltados para a coleta de amostras de equipamentos (estetoscópios e ventiladores mecânicos) ou superfícies ambientais (leito, pias), cultivo das amostras e análises microbiológicas por meio de identificação bioquímica e testes de sensibilidade aos antimicrobiano ${ }^{\text {s14-17. }}$

A inclusão de análise de outras superfícies como torneiras, mesa de cabeceira e equipamentos monitor cardíaco ${ }^{9,18}$ e, também de soluções como o sabonete liquido ${ }^{19}$ tem sido referida Destaca-se, ainda, a utilização de técnicas mais acuradas para análise nestes estudos, a exemplo da utilização da epidemiologia molecular para verificação da similaridade entre isolados bacterianos do ambiente e de pacientes ${ }^{9}$ e, a avaliação da limpeza por meio do uso do ATP bioluminescência ${ }^{18}$ que detecta a carga microbiana em superfícies em um menor intervalo de tempo quando comparado às técnicas convencionais.

Neste sentido, não se pode perder de vista que a carga microbiana das superfícies pode ser reduzida pela limpeza de rotina do ambiente atenuando a ocorrência da contaminação. Entretanto, o método de avaliação mais comum é a inspeção visual que não permite uma verificação acurada das condições de limpeza do ambiente. A frequência de descontaminação de superfícies frequentemente tocadas pode ser insatisfatória seja por indefinição de um profissional responsável pela rotina ou por se mostrarem aparentemente limpas, sendo consequentemente subestimadas ${ }^{20-21}$.

Além disso a ação dos agentes desinfetantes também deve ser considerada. Verifica-se que os isolados de MRSA e VRE podem ser sensíveis aos diversos desinfetantes disponíveis, tais como álcool e hipoclorito de sódio, nas concentrações indicadas para a desinfecção das superfícies. Entretanto, reforça-se a necessidade de atenção à remoção de sujidades e matéria orgânica que inviabilizam o processo de desinfecção. Merece, ainda, atenção as recomendações de uso dos produtos, quanto ao armazenamento, ao prazo de 
validade e, a técnica de utilização.

Em nível global as evidências da disseminação por meio da relação clonal entre isolados bacterianos de paciente e do ambiente, também tem sido descrita com a constatação de isolados idênticos de MRSA em enfermarias, em distâncias consideráveis de pacientes colonizados pelo mesmo isolado bacteriano 4 . Fatores que podem colaborar para estes achados podem ser identificados como a proximidade dos equipamentos utilizados pelos profissionais de saúde e a ausência ou baixa adesão às medidas de higienização das mãos, facilitando a disseminação dos microrganismos do paciente/equipamento para as superfícies inanimadas seja pela frequência de toque pelos profissionais e pessoas que transitam no setor, inadequada limpeza do ambiente, dos equipamentos, tipo de material, etc ${ }^{1}$.

Cuidados com equipamentos de alta frequência de uso entre pacientes como o estetoscópio devem ser pensados, pela possibilidade de carrear microrganismos, cuja medida básica, porém fundamental para interrupção desta possibilidade foi constatada em um estudo realizado em departamentos de fisioterapia de quatro hospitais da Irlanda com amostras microbiológicas do diafragma dos estetoscópios de profissionais atuantes em UTI, constatouse que naqueles estetoscópios cujo profissional relatou realizar a desinfecção com álcool 70\% não houve detecção da presença de microrganismo de relevância epidemiológica ${ }^{22}$.

Diante disso, vale a pena reforçar a importância dos investimentos em programas educativos que sensibilizem os profissionais de saúde para sua prática assistencial, tendo como meta o foco nos processos de limpeza hospitalar do ambiente, cuidados com equipamentos. $E$, sobretudo a adoção de boas práticas por estes profissionais como a monitorização contínua da higienização das mãos seja entre os profissionais de saúde e também entre pacientes e pessoas que circulam no ambiente de assistência à saúde como forma potencial de se reduzir a transferência horizontal de patógenos entre profissional, paciente e ambiente.

\section{REFEFÊNCIAS}

1. Sehulster, L. M.; Chinn, R. Y. W.; Arduino, M. J.; Carpenter, J.; Donlan, R.; Ashford, D., et al. Guidelines for environmental infection control in health-care facilities. Recommendations from Centers for Disease Control and Prevention (CDC) and the Healthcare Infection Control Practices Advisory Committee (HICPAC). Chicago, IL: American Society for Healthcare Engineering/American Hospital Association; 2004.

2. Lemmen, S. W.; Häfner, H.; Zolldann, D.; Stanzel, S.; Lüttichen, R. Distribuition of multi-resistant Gram-negative versus gram-positive bacteria in the hospital inanimate environment. J. Hosp. Infect 2004;56(3):191 -7.

3. Sexton T, Clark P, O'neill E, Dillane T, Humphreys H. Environmental reservoirs of methicillin-resistant Staphylococcus aureus in isolation rooms: correlation with patient isolates and implications for hospital hygiene. J. Hosp. Infect 2006;62(2):187-94.

4. Corona-Nakamura AL, Miranda-Novales MG, Leãnos-Miranda B. Epidemiologic study of Pseudomonas aeruginosa in critical patients and reservoirs. Arch. Med. Res 2001;32:238-42.

5. Hardy KJ, Oppenheim BA, Gossain S, Gao F, Hawkey PM. A study of the relationship between environmental contamination with Methicillin-Resistant Staphylococcus Aureus (MRSA) and patients' acquisition of MRSA. Infect. Control. Hosp. Epidemiol 2006;27(2):127-32. 6. Huang SS, Datta R, Platt R. Risk of acquiring antibiotic-resistant bacteria from prior room occupants. Arch. Inter. Med 2006;166:1945-51.

7. Organização Mundial de Saúde. World Alliance for patient Safety. WHO guidelines on hand hygiene in healthy care (advanced draft). Geneva, 2006. Disponível em: <http://www.cec.health.nsw.gov.au/files/clean-hands/resources/who-guidelines.pdf>. Acesso em: 15 abr. 2010. 8. Drees M, Snydman DR, Schmid CH, Barefoot L, Hansjosten K, Vue PM, et al. Prior environmental contamination increases the risk of acquisition of vancomycinresistant Enterococci. Clin. Infect. Dis 2008;46: 678-85. 
9. Oliveira AC, Damasceno QS, Piscoya M, Nicoli JR. Epidemiologic characteristics of resistant microorganisms present in reserves from an intensive care unit. Am J Infect Control 2011;1-3.

10. Dubberke ER, Reske KA, Noble-Wang J, Thompson A, Killgore G, Mayfield J, et al. Prevalence of Clostridium difficile environmental contamination and strain variability in multiple healthy care facilities. Am. J. Infect. Control 2007;35:315-8.

11. El Shafie SS, Alishaq M, Garcia ML. Investigation of an outbreak of multidrugresistant Acinetobacter baumannii in trauma intensive care unit. J. Hosp. Infect 2004;56: 101-5.

12. Hayden MK, Blom DW, Lyle EA, Moore CG, Weisten RA. Risk of hand or glove contamination after contact with vancomycin-resistant Enterococcus or the colonized patients' environment. Infect. Control. Hosp. Epidemiol 2008;29(2):149-54.

13. Petignat C, Francioli P, Nahimana N, Wenger A, Bille J, Schaller MD, et al. Exogenous source of Pseudomonas aeruginosa in a intensive care unit patients: implementation of infection control and follow-up with molecular typing. Infect.

Control. Hosp. Epidemiol 2006;27(9):953-7.

14. Andrade D, Angerami ELS, Padovani CR. Condição microbiológica dos leitos hospitalares antes e depois de sua limpeza. Rev Saúde Pública 2000;34 (2): 163-9.

15. Araujo BAC, Oliveira AL, Santos Filho L. Isolamento de amostras multirresistentes de staphylococcus aureus em estetoscópios usados no ambiente hospitalar. Rev Bras Anal Clin 2000;32(4): 285-8.

16. Dias MD, Pellacine EN, Zechineli CA. Aerossol bacteriano gerado por respiradores mecânicos. estudo comparativo. Rev Ass Med 1997; 43(1): 15-20.

17. Vargas FR, Carneiro AE, Petrillo VF. Aspectos da contaminação ambiental, resistência aos antimicrobianos e disseminaçäo dos bacilos Gram-negativos na infecçäo hospitalar. Pesqui méd 1985; 19(1): 23-30.

18. Ferreira AM, Andrade D, Rigotti MA, Ferrareze Ferreira MV. Condições de limpeza de superfícies próximas ao paciente, em uma unidade de terapia intensiva. Rev. Latino-Am. Enfermagem 2011; 19(3): [08 telas].

19. Caetano JA, Lima MA, Miranda MC, Serufo JC, Ponte PRL. Identificação de contaminação bacterianano sabão líquido de uso hospitalar. Rev Esc Enferm USP 2011; 45(1):153-60.

20.Carling PC, Parry, M. F; Bruno-Murta LA, Dick B. Improving environmental hygiene in 27 intensive care units to decrease multidrug-resistant bacterial transmission. Crit. Care Med 2010;38(4):1054-59.

21. BRASIL. Ministério da Saúde. Agência Nacional de Vigilância Sanitária/ANVISA. Segurança do Paciente em Serviços de Saúde - Limpeza e Desinfecção de Superfícies. 1. ed. Brasília, 2010. 120 p. Disponível em: <http://www2.rio.rj.gov.br/governo/vigilanciasanitaria/manuais/manual_seguranca_paciente_anvisa_2010.pdf >. Acesso em: 19 maio 2011.

22. Fenelon L, Holcroft L, Waters N. Contamination of stethoscopes with MRSA and current disinfection practices. J. Hosp. In fect 2009; Letter to the editor. 